\title{
Medicina / Residência Médica
}

Tem a Medicina como peculiaridade ser mescla de ciência e de arte. Como ciência pressupõe aprendizado e muito estudo, com permanente atualização. Como arte, exige vivência diuturna ao lado do paciente para, no emaranhado de queixas e diante de sinais e sintomas exibidos vislumbrar os dados importantes para confecção de diagnóstico de determinada condição patológica. Fica manifesto que maior o tirocínio maior a facilidade de identificação e tratamento das doenças.

A especialidades e sub-especialidades surgiram e se desenvolveram de forma gradual. Na medida em que os conhecimentos de determinado setor se tornaram extensos, apareceram as especialidades e ramificações das mesmas.

Para a necessária e permanente renovação de conhecimentos são valiosas nossas revistas de atualização Femina e RBGO, sempre com publicações atuais sobre os mais diversos temas, seja de Ginecologia, seja de Obstetrícia.

Aliado a este conhecimento, a permanência em Hospitais selecionados será necessária e insubstituível para o aprendizado do jovem médico. Nestes nosocômios serão aperfeiçoadas a ciência e a arte do diagnóstico e da terapêutica.

O tempo de permanência nestes Hospitais é relevante. Com a complexidade crescente das especialidades e sub-especialidades, impossível a aquisição, em curto tempo, de cabedal teórico ou prático excepcional. Impõe-se, contudo, um mínimo temporal de permanência para visão abrangente, seja da Ginecologia, seja da Obstetrícia. A posteriori, o jovem médico escolherá área específica de atuação.

É, pois, com regozijo, que vimos aprovada antiga reivindicação, e motivo de luta incessante da atual Diretoria da Febrasgo, de extensão da Residência Médica em Obstetrícia e Ginecologia para três anos. Reconhecemos que não foi alcançada a perfeição, contudo, regozijamo-nos com a conquista, importante para melhor preparo de nossos residentes.

Cientes que o médico carece de atualização permanente para o bom exercício da nobre profissão, lembramo-nos e terminamos nosso Editorial com a afirmação do notável cirurgião americano Charles Mayo em 1927: "Para ser um bom profissional o médico deverá ser um eterno estudante".

Aproveitamos o ensejo para agradecer o prestígio dedicado a nossas Revistas neste ano de 2004 e desejar a todos nossos caros associados, extensivos a todos os familiares, festas natalinas eivadas de mensagens de fraterna harmonia e ano vindouro pleno de realizações.

A Diretoria 